$5-31-2016$

\title{
Time changes in the body dimensions of male Australian Army personnel between 1977 and 2012
}

\author{
Grant Tomkinson \\ University of North Dakota, grant.tomkinson@und.edu \\ Nathan Daniell \\ Ashley Fulton \\ Alistair Furnell
}

How does access to this work benefit you? Let us know!

Follow this and additional works at: https://commons.und.edu/ehb-fac

Part of the Health and Physical Education Commons

\section{Recommended Citation}

Grant Tomkinson, Nathan Daniell, Ashley Fulton, et al.. "Time changes in the body dimensions of male Australian Army personnel between 1977 and 2012" (2016). Education, Health \& Behavior Studies Faculty Publications. 27.

https://commons.und.edu/ehb-fac/27

This Article is brought to you for free and open access by the Department of Education, Health \& Behavior Studies at UND Scholarly Commons. It has been accepted for inclusion in Education, Health \& Behavior Studies Faculty Publications by an authorized administrator of UND Scholarly Commons. For more information, please contact und.commons@library.und.edu. 


\title{
Time changes in the body dimensions of male Australian Army personnel between 1977 and 2012
}

Grant R. Tomkinson, Nathan Daniell, Ashley Fulton, Alistair Furnell

\begin{abstract}
The aim of this study was to quantify time changes in the body dimensions of male Australian Army personnel. Following a systematic review, two studies were identified and matched for occupation and age $(n=669)$ with time changes in 12 absolute and 11 proportional body dimensions assessed between 1977 and 2010-12. Changes in means were expressed as absolute, percent and standardised changes, with changes in variability assessed visually and as the ratio of coefficients of variation (CVs). Time changes in absolute dimensions were typically positive (increases) and moderate in magnitude (median standardised change $\pm 95 \%$ CI: $0.53 \pm 0.23$ ), and while changes in proportional dimensions were typically negligible (median standardised change $\pm 95 \% \mathrm{CI}: 0.16 \pm 0.33$ ), substantial changes (standardised changes $\geq 0.2$ or $\leq-0.2$ ) were observed in several dimensions. Variability in body dimensions has also typically increased (median ratio of CVs $\pm 95 \% \mathrm{CI}: 1.10 \pm 0.07$ ) and become more right-skewed. These findings have important implications for the design and acquisition of new military vehicles, body equipment and clothing.
\end{abstract}

\section{Keywords}

Time changes, Military, Anthropometry

\section{Introduction}

Time increases in body size have been well documented for people of all ages over the past couple of centuries (Cole, 2000, Cole, 2003, Danubio and Sanna, 2008, Hauspie et al., 1997, Roche, 1979). These increases in body size are believed to be due to improvements in environmental conditions, nutrition and access to health care, leading to the reduction of growthinhibiting factors (Malina, 1979, van Wieringen, 1986). Few studies however have documented time changes in professional military personnel. While time changes in body dimensions have previously been reported for Australian, British, Kenyan and US military personnel over the period 1854-2008, a small number have reported time changes for only professional military personnel (Paquette et al., 2009, Soar, 1999, Tomkinson et al., 2010) with most reporting on recruits, personnel yet to complete basic military training, or a combination thereof plus professional military personnel (e.g. Bartholomew, 1980, Cuff, 1993, Greiner and Gordon, 1992, Knapik et al., 2006, Moradi, 2009, Moroney et al., 1971, Rosenbaum and Crowdy, 1992, Steegmann, 1985). Collectively, studies of professional military personnel have examined time changes in measures of centrality (typically expressed as changes in means) and provide strong evidence for increases in the size of absolute body dimensions over time. However much less is known about time changes in variability (i.e. the spread of measurements about the middle) or time changes in proportional body dimensions (which provide an indication of changes in body shape). Despite limited published data, it has been observed that increases in the body dimensions of Royal Australian Air Force personnel were typically proportional to increases in general body size measures such as stature and mass, indicating that some military populations have increased in size but not shape over time (Tomkinson et al., 2010). This time-related pattern is expected based on geometric scaling, which theoretically suggests that time changes in body 
dimensions (e.g. lengths, breadths, circumferences and segmental heights) should approximate time changes in stature (Olds et al., 1995), assuming no meaningful time changes in cultural practises (e.g. diet and exercise). In addition, while changes in variability have rarely been reported, Tomkinson et al. (2010) showed that increases in weight, Body Mass Index (BMI), hip and waist circumference measures were non-uniform and right-skewed, with the largest time increases observed in those with the largest body size.

A lack of current anthropometric data on professional military personnel can contribute to personal equipment sizing and human machine interface design problems. For example, until recently the Australian Army were relying on old Australian datasets or newer datasets on international military populations (e.g. from the UK) for procurement specifications. This approach is limiting given: (a) a lack of evidence that the body size and shape of military personnel in one country are representative of their peers in another country; and (b) convincing evidence of recent time increases in the body size of professional military personnel from Australia and the US (Paquette et al., 2009, Tomkinson et al., 2010). An understanding of recent time changes in body dimensions has important implications for ensuring correct humanmachine (e.g. tanks, airplanes, submarines) and human-equipment (e.g. body armour and helmets) fit. The aim of this study therefore was to quantify time changes (in means and variability) in the body dimensions of male Australian Army personnel.

\section{Material and methods}

\subsection{Systematic review}

To examine time changes in the body dimensions of male Australian Army personnel, a systematic review of the scientific literature (in accordance with the PRISMA guidelines, Moher et al., 2009) was conducted to locate studies explicitly reporting descriptive anthropometric data (with a view to obtaining raw data) on all military personnel (not limited to Australia) in order to identify all possible studies that reported on male Australian Army personnel. Candidate studies were searched for in March 2014 using the following bibliographic databases: Academic Search Premier (1984-), Embase (1980-), MEDLINE (1966-), Online Defence Information Network (1950s-), PubMed (1966-), ScienceDirect (1823-), Scopus (1960-), and SPORTDiscus (1949-). The search string used for the electronic search was: ((()((()((height) OR mass) OR weight OR body size) OR girth*) OR circumference*) OR breadth*) OR length*) OR anthropometry) OR body weights and measures) OR body composition) AND ((()(((((military) OR military personnel) OR army) OR soldier*) OR armed force*) OR submariner*) OR sailor*) OR marine*) OR navy) OR air force). All available titles and abstracts were assessed for eligibility, and if there was uncertainty or the abstract was not available, then the full-text report was retrieved. Email contact was made with several Australian anthropometrists (within the Australian Defence Force [ADF] and academic institutions) to ask whether they knew of any appropriate studies. This search strategy identified 13,456 eligible studies and, following a review of all titles and abstracts, 102 studies were retained for further analysis, including several classified ADF technical reports for which appropriate declassification permissions were sought and granted. Eligible studies were excluded if descriptive anthropometric data were reported for: 
(a) non-Australian Army personnel or Australian Army personnel not able to be differentiated from other military groups (e.g. Air Force and Navy);

(b) atypical personnel or those not broadly representative of the Australian Army population (e.g. those with known injury or illness);

(c) female-only samples or mixed samples that were unable to be separated by sex;

(d) a sample previously reported in another included report;

(e) body dimensions for which explicit landmarking and measurement procedures were not available; and

(f) Australian Army personnel yet to complete basic recruit training.

Of the 102 eligible studies, 99 were excluded based on the above criteria with three studies retained for further analysis. The reference lists of these articles were examined and crossreferenced although no new studies were identified. Only studies for which raw anthropometric data were available were retained in order to best estimate time changes in measures of centrality and variability. Raw data were available for two ADF anthropometric surveys conducted in 1977 (Hendy, 1977) and 2010-12 (Tomkinson et al., 2012).

Hendy (1977) completed a tri-service (Air Force, Army and Navy) anthropometric survey of 3000 randomly sampled male permanent ADF personnel aged 17-50 years between January and November 1977. This included 1044 male Army personnel (representing 4.4\% of 23,720 permanent male Australian Army personnel) who were physically measured for 31 body dimensions. Measured Army personnel were trained and regular users of military-specific equipment and workplaces and were classified as: (a) weapons users, (b) transportation, (c) clerks and others, (d) aviation, (e) catering, and (f) technical personnel. The repeatability of the 1977 measures was very good, with nearly perfect test-retest correlations (mean Pearson's correlations $\pm 95 \% \mathrm{CI}: 0.95 \pm 0.01)$ (Hendy, 1977).

Tomkinson et al. (2012) completed a large anthropometric survey (the Australian Warfighter Anthropometric Survey [AWAS]) of 2138 permanent Australian Army personnel aged 18-40 years who were recruited from five Army bases between July 2010 and April 2012. This included 1861 males (representing 6.9\% of 26,994 permanent male Army personnel) and 277 females (representing 9.1\% of 3042 permanent female Army personnel) who were physically and digitally measured for 84 body dimensions. Recruited male personnel represented 15 Corps and 70 trades, with 93\% (1732 of 1861) born in either Australia or New Zealand and the remainder born in Asia (2\%), Europe (2\%), the Pacific Islands (1\%) or other countries (2\%). The repeatability of the 2010-12 measures was very good, with very small systematic errors (median percent changes in means $\pm 95 \% \mathrm{CI}: 0.02 \pm 0.04 \%$ ), very small random errors (median percent typical errors $\pm 95 \% \mathrm{CI}: 0.47 \pm 0.07 \%$ ), and nearly perfect test-retest correlations (median intraclass correlations $\pm 95 \%$ CI: $0.996 \pm 0.001$ ) (Tomkinson et al., 2012). 


\subsection{Initial data analysis}

Prior to calculating time changes, all raw data were checked and cleaned to ensure quality. For consistency between datasets, all female data (13\% or 277 of 2138) in the 2010-12 dataset, and all data on males not aged 18-40 years (8\% or 85 of 1044) in the 1977 dataset, were excluded. Thirdly, all raw data were checked for anomalies by running range checks with data \pm 3 standard deviations away from the mean identified as being potentially anomalous. However, following visual examination of scatterplots relating each dimension to Stature (or Sitting Height for seated measurements) and Weight, potentially anomalous data were considered to be acceptable and were retained for further analysis.

A comparison of two surveys revealed that 12 of 31 absolute body dimensions measured in 1977 were identically measured in 2010-12 using the same measurement protocols and equipment, including four heights, three circumferences, three breadths, one length and Weight. All absolute body dimensions (except Stature) were normalised as a fraction of Stature (note, Weight was normalised to Stature as the BMI) using geometric scaling - the most common form of allometry - to eliminate the effect of general body size, resulting in 11 proportional body dimensions (Olds et al., 1995). To reduce potential systematic biases, comparative data would ideally be standardised by occupation, age and demographics to the permanent Australian Army populations at the time of measurement. However, without access to census data at the occupation by age level from both time points, the two samples were instead matched by occupation and age to control for occupation- and age-related differences in body size. For consistency with the 1977 survey, and to allow for occupation-based matching, all occupationbased data in 2010-12 were reclassified based on 1977 criteria (e.g. a Commando was reclassified as a weapons user). Using a greedy matching procedure (Gu and Rosenbaum, 1993), the two datasets were matched one-for-one for occupation and decimal age, yielding 669 matched pairs. To check that the matching procedures worked, time changes in occupation were calculated using Pearson's chi-square analysis (alpha set at 5\%) with time changes in age calculated using the procedures described in the next paragraph.

\subsection{Statistical analysis}

Changes in means and variability between 1977 and 2010-12 were calculated using the procedures described by Tomkinson et al. (2010). Levene's test was used to examine equality of variance between groups, with the unpaired $t$-tests used to examine equality of means for groups with equal variances and Aspin-Welch unequal variance $t$-tests used for groups with unequal variances. Changes in means were calculated as absolute, percent and standardised changes. Absolute changes were calculated as the difference in means (2010-12 mean minus 1977 mean); percent changes as the absolute changes expressed as a percentage of the overall mean (i.e. the mean of the combined datasets); and standardised changes as the absolute changes divided by the pooled standard deviation. Positive changes indicated time increases in mean values and negative changes indicated time declines. Standardised changes were qualitatively interpreted using thresholds of $0.2,0.5$ and 0.8 as small, moderate and large respectively, with changes $<0.2$ (or $>-$ 0.2 ) considered to be negligible and changes $\geq 0.2$ (or $\leq-0.2$ ) considered to be 'substantial' (i.e. the smallest important change) (Cohen, 1988). For the sake of parsimony, we report only changes that were substantial. The $95 \%$ confidence interval $(95 \% \mathrm{CI})$ for an absolute change was calculated as the absolute change \pm 1.96 multiplied by the standard error of difference; the $95 \% \mathrm{CI}$ 
for a percent change as the percent change \pm 1.96 multiplied by the standard error of difference expressed as a percentage of the overall mean value; and the 95\%CI for a standardised change by the method described by Cumming (2012). The chances that the standardised changes were substantial (i.e. $\geq 0.2$ or $\leq-0.2$ ) were also calculated (Hopkins, 2007), with chances qualitatively interpreted using thresholds described by Hopkins (2002).

The variability of measurements about the mean value was quantified as the coefficient of variation $(\mathrm{CV}$; the standard deviation divided by the mean), with time changes in variability calculated as the ratio of CVs by dividing the $2010-12$ CV by the $1977 \mathrm{CV}$. The $95 \% \mathrm{CI}$ of the ratio of CVs was calculated using the method described by Hopkins (2007). Ratios $\geq 1.1$ indicated substantial time increases in variability, ratios $\leq 0.9$ indicated substantial time declines in variability, and ratios between 0.9 and 1.1 indicated negligible time changes in variability (Drinkwater et al., 2007). The chances that the true ratios were substantial (i.e. $\geq 1.1$ or $\leq 0.9$ ) were also calculated (Hopkins, 2007), with chances qualitatively interpreted using thresholds described by Hopkins (2002). Changes in variability were also examined visually using Lowess curves (tension $=66$ ), by plotting the standardised changes for a range of percentiles (from 1 to 99) against the percentiles themselves. Lowess curves are model-free curves of best fit that are determined by the "gravitational pull" of data points in each local area of the curve (Cleveland and Devlin, 1988).

\section{Results}

\subsection{Changes in means}

There were negligible time changes in the occupation and age matching criteria, which confirmed that the matching procedure worked. Changes in means in absolute dimensions of male Australian Army were typically small (median standardised change $\pm 95 \%$ CI: $0.53 \pm 0.23$ ) when matched for occupation and age, with large increases (standardised changes $\geq 0.80$ ) observed for one dimension, moderate increases (standardised changes 0.50 to 0.79 ) for six dimensions, small increases (standardised changes 0.20 to 0.49 ) for three dimensions, and negligible changes (standardised changes -0.19 to 0.19 ) for two dimensions (Table 1). Examination of Table 1 reveals that the moderate increase in Stature $(37 \pm 7 \mathrm{~mm})$ can be largely explained by moderate increases in Sitting Height $(21 \pm 4 \mathrm{~mm})$ and Buttock-Knee Length $(15 \pm 3 \mathrm{~mm})$, given the negligible change in Popliteal Height $(-2 \pm 3 \mathrm{~mm})$.

On average, changes in means in proportional dimensions were negligible (median standardised change $\pm 95 \% \mathrm{CI}: 0.16 \pm 0.33$ ), indicating that body dimensions changed at a similar rate to Stature over time. However, there were moderate increases in proportionality for Bideltoid Breadth (standardised change $\pm 95 \%$ CI: $0.64 \pm 0.11$ ) and Weight (operationalised as the BMI) (standardised change $\pm 95 \% \mathrm{CI}: 0.56 \pm 0.11$ ), small increases for Hip Breadth (Sitting) (standardised change $\pm 95 \% \mathrm{CI}: 0.38 \pm 0.11$ ), Waist Circumference Omphalion (standardised change $\pm 95 \% \mathrm{CI}: 0.26 \pm 0.11$ ) and Buttock Circumference (standardised change $\pm 95 \% \mathrm{CI}: 0.20$ \pm 0.11 ), and moderate-to-large declines for Head Circumference (standardised change $\pm 95 \% \mathrm{CI}$ : $-0.59 \pm 0.11$ ) and Politeal Height (standardised change $\pm 95 \% \mathrm{CI}:-0.82 \pm 0.11$ ). 
Table 1. Changes in means and CVs in male Australian Army personnel matched by occupation and age between 1977 and $2010-12$.

\begin{tabular}{|c|c|c|c|c|c|c|c|c|c|c|}
\hline \multirow[t]{2}{*}{ Body dimension } & \multicolumn{2}{|c|}{1977} & \multicolumn{2}{|c|}{ 2010-12 } & \multicolumn{3}{|c|}{ Change in means $\pm 95 \% \mathrm{CI}$} & \multirow{2}{*}{$\begin{array}{l}\text { Chances of } \\
\text { substantial } \\
\text { changes in means }\end{array}$} & \multirow{2}{*}{$\begin{array}{l}\text { Ratio } \\
\text { of } C V s \mathrm{~s} / \div \\
95 \% \mathrm{CI}\end{array}$} & \multirow{2}{*}{$\begin{array}{l}\text { Chances of } \\
\text { substantial } \\
\text { changes in } \mathrm{CVs}\end{array}$} \\
\hline & $n$ & $x \pm s$ & $n$ & $x \pm s$ & Absolute & Percent & Standardised & & & \\
\hline $\begin{array}{l}\text { Bideltoid breadth } \\
(\mathrm{mm})\end{array}$ & 669 & $470 \pm 25$ & 669 & $497 \pm 27$ & $27 \pm 3$ & $5.8 \pm 0.6$ & $1.03 \pm 0.11$ & $\begin{array}{l}\text { 100\%: almost } \\
\text { certainly } \\
\text { substantial increase }\end{array}$ & $1.04 \times / \div 1.08$ & $\begin{array}{l}6 \% \text { : unlikely } \\
\text { substantial increase }\end{array}$ \\
\hline Weight (kg) & 669 & $74.6 \pm 10.8$ & 669 & $83.7 \pm 12.5$ & $9.1 \pm 1.2$ & $12.2 \pm 1.7$ & $0.78 \pm 0.11$ & $\begin{array}{l}\text { 100\%: almost } \\
\text { certainly } \\
\text { substantial increase }\end{array}$ & $1.03 \times / \div 1.08$ & $\begin{array}{l}\text { 5\%: unlikely } \\
\text { substantial increase }\end{array}$ \\
\hline $\begin{array}{l}\text { Hip breadth } \\
\text { (Sitting) }(\mathrm{mm})\end{array}$ & 669 & $357 \pm 22$ & 669 & $374 \pm 30$ & $17 \pm 3$ & $4.8 \pm 0.8$ & $0.65 \pm 0.11$ & $\begin{array}{l}\text { 100\%: almost } \\
\text { certainly } \\
\text { substantial increase }\end{array}$ & $1.32 \times / \div 1.08$ & $\begin{array}{l}\text { 100\%: almost } \\
\text { certainly } \\
\text { substantial increase }\end{array}$ \\
\hline Sitting height (mm) & 669 & $914 \pm 32$ & 669 & $935 \pm 34$ & $21 \pm 4$ & $2.3 \pm 0.4$ & $0.63 \pm 0.11$ & $\begin{array}{l}\text { 100\%: almost } \\
\text { certainly } \\
\text { substantial increase }\end{array}$ & $1.04 \times / \div 1.08$ & $\begin{array}{l}8 \%: \text { unlikely } \\
\text { substantial increase }\end{array}$ \\
\hline Stature $(\mathrm{mm})$ & 669 & $1747 \pm 61$ & 669 & $1785 \pm 70$ & $37 \pm 7$ & $2.1 \pm 0.4$ & $0.57 \pm 0.11$ & $\begin{array}{l}\text { 100\%: almost } \\
\text { certainly } \\
\text { substantial increase }\end{array}$ & $1.13 \times / \div 1.08$ & $\begin{array}{l}74 \% \text { : possibly } \\
\text { substantial increase }\end{array}$ \\
\hline $\begin{array}{l}\text { Buttock-knee length } \\
(\mathrm{mm})\end{array}$ & 669 & $601 \pm 26$ & 669 & $616 \pm 29$ & $15 \pm 3$ & $2.6 \pm 0.5$ & $0.56 \pm 0.11$ & $\begin{array}{l}\text { 100\%: almost } \\
\text { certainly } \\
\text { substantial increase }\end{array}$ & $1.12 \times / \div 1.08$ & $\begin{array}{l}66 \% \text { : possibly } \\
\text { substantial increase }\end{array}$ \\
\hline $\begin{array}{l}\text { Buttock } \\
\text { circumference } \\
(\mathrm{mm})\end{array}$ & 669 & $973 \pm 63$ & 669 & $1006 \pm 70$ & $34 \pm 7$ & $3.5 \pm 0.7$ & $0.51 \pm 0.11$ & $\begin{array}{l}\text { 100\%: almost } \\
\text { certainly } \\
\text { substantial increase }\end{array}$ & $1.08 \times / \div 1.08$ & $\begin{array}{l}28 \% \text { : possibly not } \\
\text { substantial increase }\end{array}$ \\
\hline $\begin{array}{l}\text { Waist } \\
\text { circumference } \\
\text { omphalion }(\mathrm{mm})\end{array}$ & 669 & $862 \pm 88$ & 669 & $905 \pm 101$ & $43 \pm 10$ & $4.9 \pm 1.2$ & $0.45 \pm 0.11$ & $\begin{array}{l}\text { 100\%: almost } \\
\text { certainly } \\
\text { substantial increase }\end{array}$ & $1.08 \times / \div 1.08$ & $\begin{array}{l}\text { 35\%: possibly not } \\
\text { substantial increase }\end{array}$ \\
\hline $\begin{array}{l}\text { Thigh clearance } \\
(\mathrm{mm})\end{array}$ & 669 & $172 \pm 13$ & 669 & $177 \pm 15$ & $5 \pm 1$ & $2.6 \pm 0.9$ & $0.33 \pm 0.11$ & $\begin{array}{l}\text { 99\%: very likely } \\
\text { substantial increase }\end{array}$ & $1.15 \times / \div 1.08$ & $\begin{array}{l}88 \% \text { : likely } \\
\text { substantial increase }\end{array}$ \\
\hline Foot breadth (mm) & 669 & $99 \pm 5$ & 669 & $100 \pm 6$ & $2 \pm 1$ & $1.6 \pm 0.6$ & $0.30 \pm 0.11$ & $\begin{array}{l}\text { 96\%: very likely } \\
\text { substantial increase }\end{array}$ & $1.28 \times / \div 1.08$ & $\begin{array}{l}\text { 100\%: almost } \\
\text { certainly } \\
\text { substantial increase }\end{array}$ \\
\hline $\begin{array}{l}\text { Popliteal height } \\
(\mathrm{mm})\end{array}$ & 669 & $447 \pm 22$ & 669 & $445 \pm 26$ & $-2 \pm 3$ & $-0.5 \pm 0.6$ & $-0.09 \pm 0.11$ & $\begin{array}{l}2 \% \text { : very unlikely } \\
\text { substantial decline }\end{array}$ & $1.19 \times / \div 1.08$ & $\begin{array}{l}\text { 98\%: very likely } \\
\text { substantial increase }\end{array}$ \\
\hline $\begin{array}{l}\text { Head circumference } \\
(\mathrm{mm})\end{array}$ & 669 & $573 \pm 15$ & 669 & $572 \pm 16$ & $-1 \pm 2$ & $-0.2 \pm 0.3$ & $-0.09 \pm 0.11$ & $\begin{array}{l}2 \% \text { : very unlikely } \\
\text { substantial decline }\end{array}$ & $1.01 \times / \div 1.08$ & $\begin{array}{l}1 \% \text { : very unlikely } \\
\text { substantial increase }\end{array}$ \\
\hline
\end{tabular}

Note: positive changes in means indicate time increases in mean values and negative changes indicate time declines; changes in means $\geq 0.2$ indicate substantial time increases in mean values and changes $\leq-0.2$ indicate substantial time declines; ratio of CVs $\geq 1.1$ indicate substantial time increases in variability and ratios $\leq 0.9$ indicate substantial time declines; $n=$ sample size; $x=$ mean; $s=$ standard deviation; $\mathrm{CV}=$ coefficient of variation; $95 \% \mathrm{CI}=95 \%$ confidence interval; $95 \% \mathrm{CI}$ for ratios are represented as $\mathrm{x} / \div 95 \% \mathrm{CI}$; all absolute changes in means represent changes in $\mathrm{mm}$, except changes in Weight which are in $\mathrm{kg}$; thresholds for assigning qualitative terms to chances of substantial changes in means and CVs were as follows: $<1 \%=$ almost certainly not; $<5 \%=$ very unlikely; $<25 \%=$ unlikely; $<50 \%=$ possibly not; $>50 \%=$ possibly; $>75 \%=$ likely; $>95 \%=$ very likely; $>99 \%=$ almost certainly (Hopkins, 2002). 


\subsection{Changes in variability}

There were typically substantial increases in variability (median ratio of CVs $\pm 95 \% \mathrm{CI}: 1.10 \pm 0.07$ ) between 1977 and 2010-12, with substantial increases observed for Hip Breadth (Sitting), Foot Breadth, Popliteal Height, Thigh Clearance, Stature and Buttock-Knee Length (Table 1). Fig. 1 shows that time changes in body dimensions were typically non-uniform and right-skewed, as indicated by the high number of non-linear or upward sloping Lowess curves (e.g. Stature, Weight, Buttock Circumference, and Hip Breadth [Sitting]), relative to the low number of linear or flat curves indicating uniform changes (e.g. Head Circumference). These results indicate that larger time changes were observed in the higher percentiles $(>75$ th, i.e. larger males) than for the middle $(25-75$ th, i.e. average males $)$ and lower $(<25$ th, i.e. smaller males) percentiles.

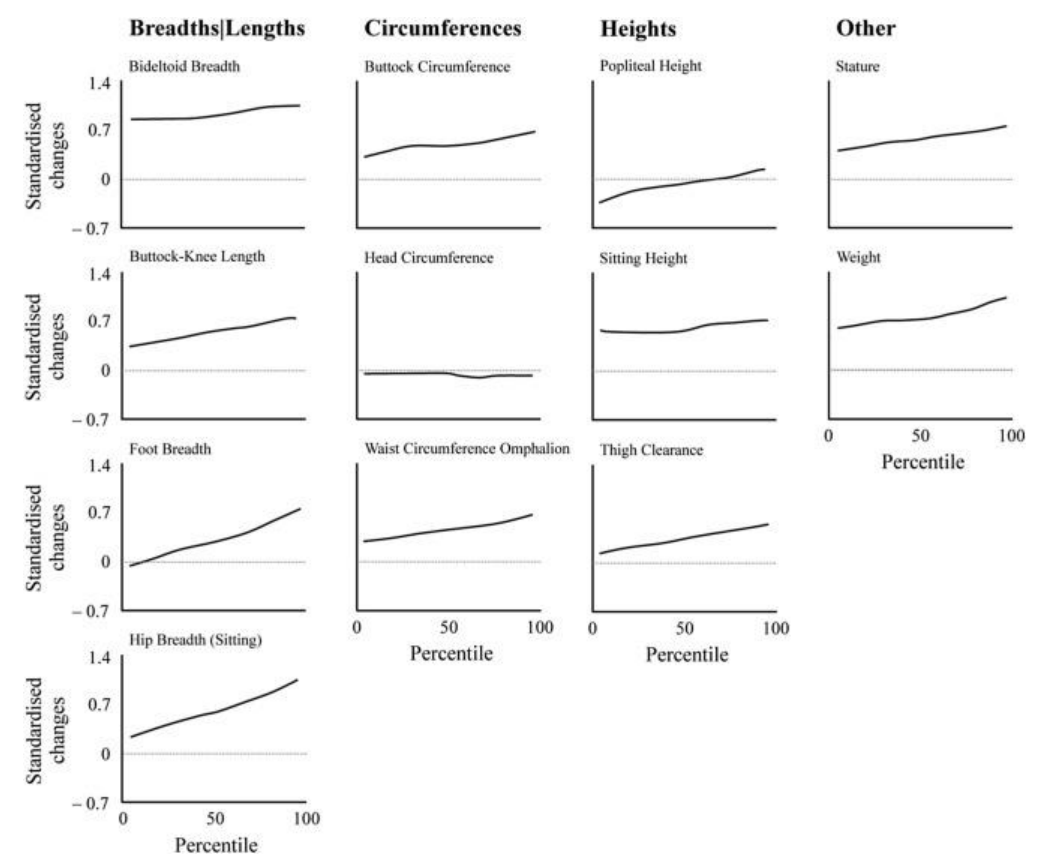

Fig. 1. Time changes in variability in male Australian Army personnel matched by occupation and age between 1977 and 2010-12. The vertical axis shows the standardised changes, with positive values indicating time increases and negative values indicating time declines. The horizontal axis shows the percentile values (range: 1-99). Lowess curves (tension= 66) are also shown.

\section{Discussion}

This is the first study to quantify time changes in numerous body dimensions of male Australian Army personnel. It showed that: (a) absolute body dimensions typically increased over time; (b) changes in body dimensions were typically non-uniform and right-skewed; and (c) while changes in proportionality were typically negligible, substantial changes were observed in several dimensions.

Few studies examining time changes in body dimensions of military populations have examined as many dimensions as those in this study, both absolute and proportional body dimensions, or tracked changes over such a long time period. In this study, time changes in identically measured body dimensions were examined by two trained measurement teams that demonstrated very good repeatability. While this study employed a matching procedure to control for methodological bias it unfortunately could only examine linear changes between two time points, making it impossible to determine the exact nature of the changes. Ideally, time changes should be examined between random samples that are representative of their source populations. While this study examined time changes in two non-random samples, it does at 
least provide an estimate of time changes in two samples that represent reasonable cross-sections of the male Australian Army population at each time point (ranging from 4.4\% in 1977 to $6.9 \%$ in 2010-12).

Possible time changes in the ethnic mix of the Australian Army population may have systematically biased the time changes reported in this study, given a concurrent decline in the proportion of Australianborn citizens (Australian Bureau of Statistics, 2013) and known ethnic differences in body size and shape (Misra et al., 2005, Wells et al., 2008). Unfortunately, time changes in ethnic mix could not be quantified because ethnicity data (operationalised as the country of birth) were not collected in 1977. Time changes in body dimensions could have been affected by changes in Army recruitment strategies and entrance/work-related standards, which act to truncate the tails of the distribution especially the right tail or high percentiles of the distribution. Given that recruitment standards have remained unchanged in the Australian Army since 1977 (except BMI for which a maximum threshold of $33 \mathrm{~kg} \mathrm{~m}^{-2}$ was recently imposed), it is unlikely that the reported time changes were systematically biased. In fact, the recently imposed maximum threshold for BMI should have reduced variability and right-skew over time, although Fig. 1 provides evidence of a time increase in right-skew.

\subsection{Time comparisons}

In order to compare time changes between male Australian Army personnel and other Australian and international military populations, we conducted a secondary systematic review identical to the primary review defined in the Methods with the addition of the following search string: ((((AND (trend*) OR secular) OR time) OR change*) OR temporal). This secondary systematic review identified two studies that reported time changes (using identical measurement protocols and tracked over a several decades) in representative samples of: (a) male Royal Australian Air Force(RAAF) aircrew $(n=440)$ tested over the period 1971-2005 (Tomkinson et al., 2010); and (b) male US Army personnel $(n=2425)$ tested over the period 1988-2008 (Paquette et al., 2009). Table 2 compares the time changes for 11 body dimensions (10 absolute and one proportional) between male Australian Army personnel and their male peers from the RAAF and the US Army. The standardised time changes (corrected to a 35-year period) were similar in direction (typically indicating time increases) yet somewhat different in magnitude, with small differences on average compared to RAAF personnel (mean standardised difference $\pm 95 \% \mathrm{CI}$ : $0.26 \pm 0.08$ ) and negligible differences compared to US Army personnel (mean standardised difference $\pm 95 \%$ CI: $0.08 \pm 0.38$ ) in favour of larger time increases in Australian Army personnel. An interesting observation from Table 2 is that the substantial increase in Stature in both Australian Army and RAAF personnel has been the result of substantial increases in both Sitting Height and ButtockKnee Length. While there is some evidence suggesting that time increases in stature are largely due to increases in leg length (Himes, 1979, Tanner et al., 1982), this study found no meaningful changes in both proportional Sitting Height and proportional Buttock-Knee Length, suggesting that increases in Stature in Australian Army personnel are similarly due to increases in both dimensions. In contrast, there has been no meaningful change in Stature in US Army personnel in recent decades, which is expected given the negligible to small changes in Sitting Height and Buttock-Knee Length. 
Table 2. Comparisons of time changes (expressed as absolute and standardised [shown in brackets] changes in means over a 35-year period) between male Australian Armypersonnel (1977-2012) and their male peers from the Royal Australian Air Force (RAAF: 1971-2005) and the US Army (1988-2008).

\begin{tabular}{|c|c|c|c|}
\hline \multirow[t]{2}{*}{ Body dimension } & \multicolumn{3}{|c|}{ Absolute [and standardised] changes in means over a 35-year period } \\
\hline & Australian army & RAAF & US army \\
\hline Bideltoid breadth (mm) & $27[1.03]$ & NA & $18[0.63]$ \\
\hline BMI $\left(\mathrm{kg} \mathrm{m}^{-2}\right)$ & $1.8[0.56]$ & $0.8[0.30]$ & NA \\
\hline Buttock circumference (mm) & $34[0.51]$ & $26[0.30]$ & $79[1.20]$ \\
\hline Buttock-knee length (mm) & $15[0.56]$ & $8[0.30]$ & $1[0.02]$ \\
\hline Foot breadth $(\mathrm{mm})$ & $2[0.30]$ & NA & $-1[-0.16]$ \\
\hline Head circumference (mm) & $-1[-0.09]$ & $-8[-0.56]$ & NA \\
\hline Hip breadth, sitting (mm) & $17[0.65]$ & NA & $11[0.39]$ \\
\hline Sitting height (mm) & $21[0.63]$ & $11[0.32]$ & $8[0.23]$ \\
\hline Stature $(\mathrm{mm})$ & $37[0.57]$ & $27[0.44]$ & $-1[-0.01]$ \\
\hline Waist circumference omphalion (mm) & $43[0.45]$ & $26[0.31]$ & $136[1.45]$ \\
\hline Weight (kg) & $9.1[0.78]$ & $5.0[0.48]$ & $12[0.98]$ \\
\hline
\end{tabular}

Note: shown are comparative time change data for male RAAF aircrew $(n=440)$ between 1971 and 2005 (Tomkinson et al., 2010) and male US Army personnel $(n=2425)$ between 1988 and 2008 (Paquette et al., 2009). Time changes in RAAF and US Army personnel were expressed as changes in means over a 35-year period by multiplying the reported changes by a time factor of 1.03 and 1.75 , respectively. The second, third and fourth columns show the absolute and standardised changes in means over a 35-year period (for consistency with the time changes reported in this study), with positive values indicating time increases in mean values and negative values indicating time declines.

Another interesting observation from Table 2 is the substantial time increases in Weight, BMI, and Waist Circumference Omphalion, which range from small to moderate in magnitude for Australian Army and RAAF personnel and were large for US Army personnel. In this study both absolute and proportional Waist Circumference Omphalion increased substantially over time, indicating that both waist size and shape have recently increased in Australian Army personnel. While analysis of time changes in direct measures of fat mass was not possible, time increases in these three indirect measures are probably largely due to increases in fat mass. Cross-sectionally in apparently healthy adults, BMI and waist circumference are almost perfectly correlated with one another and with fat mass, and both are very highly correlated with abdominal visceral fat (Bouchard, 2007). Given that BMI and waist circumference are strongly and positively related to cardiovascular disease and all-cause mortality, these recent time increases suggest that today's military personnel are at greater risk of developing chronic conditionslater in life (World Health Organisation, 2000).

An additional comparison between Australian Army and RAAF personnel revealed that the general time increase in variability observed in Australian Army personnel was not observed in RAAF personnel, although there was evidence of non-uniform and right-skewed time increases in both populations (e.g. for Weight, BMI, Waist Circumference Omphalion and Buttock Circumference). Furthermore, an analysis of data from five cross-sectional, population-based surveys (using direct measures of Stature and Weight, plus derived BMI) of young adult Australian males (aged 25-44 years) over the period 1980-2000 (Australian Bureau of Statistics, 1997, Cameron et al., 2003, National Heart Foundation of Australia, 1981, National Heart Foundation of Australia, 1985, National Heart Foundation of Australia, 1990) reveals that time changes in male Australian Army personnel were substantially larger for Stature (standardised changes: 0.57 vs. -0.01 ) and Weight (standardised changes: 0.78 vs. 0.44 ) yet similar for 
BMI (standardised changes: 0.56 vs. 0.54 ) relative to their peers from the general population. Differences in time changes between male Australian Army personnel and their peers from the general population may be due to differences in changes in ethnic mix, the time span over which the changes were calculated, or sampling bias as a result of military recruitment strategies and entrance/work-related standards.

\subsection{Implications}

Time increases in body dimensions of military populations have important implications for the design and acquisition of new military platforms (e.g. land, sea and air vehicle platforms). When humans change in size and shape, the built environment often adapts (slowly) in response, especially for equipment or infrastructure designed to last several decades or more. Because of the substantial costs, specialised land, sea and air vehicles are usually designed to have a lifespan of several decades. Due to the lengthy development periods for military vehicle platforms, the anthropometric data used to guide the design of a vehicle may be relatively old when the vehicle enters service which may result, for example, in a soldier driving a land vehicle that was designed using anthropometric data that are several decades old. Given the recent time increases in the absolute body dimensions of male Australian Army personnel, especially substantial increases (in means and right-skew) in the dimensions that are traditionally considered important determinants of platform fit and ergonomic design (e.g. Stature, Sitting Height, and Buttock-Knee Length), the pool of available Australian Army personnel that can fit into and safely operate a land vehicle has probably shrunk over the life of most vehicles. Theoretically, the same problem would also occur in other military populations that are increasing in size and working in other confined environments, such as RAAF aircrew working in aircraft or Australian Navy seamen working in submarines (Tomkinson et al., 2010). Ideally, the body dimensions of current military personnel, along with an estimate of the size of the personnel at the end of the planned service life of military vehicles (through time change analysis) should be considered when acquiring or designing new military vehicles or when upgrading existing military vehicles. This will optimise the number of military personnel who can fit into and safely operate the vehicles both now and in the future. Furthermore, whilst time changes might affect ergonomic aspects such as fit, task performance and posture, they are also important for survivability modeling. For example, this study showed that between 1977 and 2012 there was a moderate increase in Sitting Height of $21 \pm 4 \mathrm{~mm}$, with increases in Sitting Height affecting ceiling clearance and the potential for head injury during a blast event.

The results of this study highlight the need for updated military anthropometric recruitment standards to most accurately reflect fit requirements for current military vehicles. The recent time changes in body dimensions of Australian Army personnel observed in this study and in other Australian (e.g. RAAF aircrew) (Tomkinson et al., 2010) and international military populations (e.g. US Army personnel) (Paquette et al., 2009) emphasise that the sizing and design of clothing and protective equipment items such as body armour, helmets, and G-suits (worn by fast jet pilots to help prevent loss of consciousness during high G-force maneuvers) should be reviewed periodically, to ensure correct human-equipment fit.

\section{Conclusion}

This study showed that there were substantial changes (typically increases) in the body dimensions of male Australian Army personnel over the period 1977-2012, changes that were generally non-uniform and right-skewed across the distribution. In addition to increases in body size, there was also evidence of changes in body shape, as evidenced by the substantial changes in several proportional body dimensions. Time changes in male Australian Army personnel are similar in direction yet marginally different in magnitude to those observed in other Australian and international military populations. These findings 
have important implications for the design and acquisition of new military vehicles and the design of protective body equipment and clothing, stressing the need for regular anthropometric surveying of military personnel.

\section{Acknowledgment}

The Defence Science and Technology Group (DSTG) of the Department of Defence supported this study as part of a larger project entitled the "Australian Warfighter Anthropometric Survey".

\section{References}

Australian Bureau of Statistics, 1997. National Nutrition Survey: Selected Highlights 1995. Australian Government Publishing Service, Canberra.

Australian Bureau of Statistics, 2013. Reflecting a Nation: Stories from the 2011 Census. Australian Government Publishing Service, Canberra.

Bartholomew, J., 1980. The Effects of Multiple Anthropometric Constraints on the Accomodation of Personnel in Operational Naval Aircraft, Operations Research. Naval Postgraduate School, San Fransisco.

Bouchard, C., 2007. BMI, fat mass, abdominal adiposity and visceral fat: where is the 'beef'? Int. J. Obes. Relat. Metabolic Disord. 31, 1552-1553.

Cameron, A., Welborn, T., Zimmet, P., Dunstand, D., Owen, N., Salmon, J., Dalton, M., Jolley, D., Shaw, J., 2003. Overweight and obesity in Australia: the 1999e2000australian diabetes, obesity and lifestyle study (AusDiab). Med. J. Aust. 178,427-432.

Cleveland, W., Devlin, S., 1988. Locally weighted regression: an approach to regression analysis by local fitting. J. Am. Stat. Assoc. 83, 596-610.

Cohen, J., 1988. Statistical Power Analysis for the Behavioral Sciences, second ed. Lawrence Erlbaum, Hillsdale, NJ.

Cole, T., 2000. Secular trends in growth. Proc. Nutr. Soc. 59, 317-324.

Cole, T., 2003. The secular trend in human physical growth: a biological view. Econ. Hum. Biol. 1, 161168.

Cuff, T., 1993. The body mass index values of mid-nineteenth century West Point cadets. Hist. methods 26, 171-182.

Cumming, G., 2012. Understanding the New Statistics: Effect Sizes, Confidence In-tervals, and Metaanalysis. Taylor \& Francis, London.

Danubio, M., Sanna, E., 2008. Secular changes in human biological variables in Western Countries: an updated review and synthesis. J. Anthropol. Sci. 86,91-112.

Drinkwater, E., Hopkins, W., McKenna, M., Hunt, P., Pyne, D., 2007. Modelling age and secular differences in fitness between basketball players. J. Sports Sci. 25,869-878.

Greiner, T., Gordon, C., 1992. Secular trends of 22 body dimensions in four racial/cultural groups of American males. Am. J. Hum. Biol. 4, 235-246. 
Gu, X., Rosenbaum, P., 1993. Comparison of multivariate matching methods: structures, distances and algorithms. J. Comput. Graph. Statistics 2, 405e420.

Hauspie, R., Vercauteren, M., Susanne, C., 1997. Secular changes in growth andmaturation: an update. Acta Paediatr. Suppl. 423, 20e27.

Hendy, K., 1977. Australian Tri-service Anthropometric Survey, 1977: Part 1. Survey Planning, Conduct, Data Handling and Methods of Analysis. Defence Science and Technology Organisation, Melbourne.

Himes, J.H., 1979. Secular changes in body proportions and composition. In: Roche, A. (Ed.), Secular Trends in Human Growth, Maturation, and Develop-ment. University of Chicago Press, Chicago, IL, pp. 28-58.

Hopkins, W., 2002. A Scale of Magnitudes for Effect Statistics. Sportscience.

Hopkins, W., 2007. A spreadsheet for deriving a confidence interval, mechanisticinference and clinical inference from a $\mathrm{p}$ value. Sportscience 11, 16-20.

Knapik, J., Sharp, M., Darakjy, S., Jones, S., Hauret, K., Jones, B., 2006. Temporal changes in the physical fitness of US Army recruits. Sports Med. 36, 613-634.

Malina, R., 1979. Secular changes in size and maturity: causes and effects. In: Roche, A. (Ed.), Secular Trends in Human Growth, Maturation, and Develop-ment. University of Chicago Press, Chicago, IL, pp. 59-120.

Misra, A., Wasir, J., Vikram, N., 2005. Waist circumference criteria for the diagnosisof abdominal obesity are not applicable uniformly to all populations and ethnicgroups. Nutrition 21, 969-976.

Moher, D., Liberati, A., Tetzlaff, J., Altman, D., Group, The PRISMA., 2009. Preferred reporting items for systematic reviews and meta-analyses: the PRISMA statement. PLoS Med. 6, e1000097.

Moradi, A., 2009. Towards an objective account of nutrition and health in colonial Kenya: a study of stature in african army recruits and civilians, 1880-1980.J. Econ. Hist. 69, 719-754.

Moroney, W., Kennedy, R., Gifford, E., Provost, J., 1971. Selected Anthropometric Dimensions of Naval Aviation Personnel. Naval Aerospace Medical Research Laboratory, Pensacola.

National Heart Foundation of Australia, 1981. Risk Factor Prevalance Study: Report no.1-1980. National Heart Foundation of Australia, Canberra.

National Heart Foundation of Australia, 1985. Risk Factor Prevalence Study: Report no.2-1983. National Heart Foundation of Australia, Canberra.

National Heart Foundation of Australia, 1990. Risk Factor Prevalence Study: Report no.3-1989. National Heart Foundation of Australia, Canberra.

Olds, T., Norton, K., Van Ly, S., Lowe, L., 1995. Similarity systems in anthropometry. In: Norton, K., Olds, T. (Eds.), Anthropometrica. University of New South Wales Press, Sydney, NSW, pp. 121-145.

Paquette, S., Gordon, C., Bradtmiller, B., 2009. Anthropometric Survey (ANSUR) II Pilot Study: Methods and Summary Statistics. US Army Natick Soldier Research, Development and Engineering Center, Natick, MA. 
Roche, A., 1979. Secular trends in stature, weight, and maturation. In: Roche, A. (Ed.), Secular Trends in Human Growth, Maturation, and Development. University of Chicago Press, Chicago, IL, pp. 327.

Rosenbaum, S., Crowdy, J., 1992. British Army recruits: 100 years of heights and weights. J. R. Army Med. Corps 138, 81-86.

Soar, N., 1999. An examination of the secular trend in Australian male stature as seen in the military data. Perspect. Hum. Biol. 4, 157-166.

Steegmann Jr., A., 1985. 18th Century British military stature: growth cessation, selective recruiting, secular trends, nutrition at birth, cold and occupation. Hum. Biol. 57, 77-95.

Tanner, J.M., Hayashi, T., Preece, M.A., Cameron, N., 1982. Increase in length of legrelative to trunk in Japanese children and adults from 1957 to 1977: comparison with British and with Japanese Americans. Ann. Hum. Biol. 9, 411-423.

Tomkinson, G., Clark, A., Blanchonette, P., 2010. Secular changes in body dimensions of royal australian air force aircrew (1971-2005). Ergonomics 53, 994-1005.

Tomkinson, G., Daniell, N., Dale, M., Bowler, T., 2012. Australian Warfighter Anthropometry Survey (AWAS): Methods, Temporal Changes and Summary Statistics. University of South Australia, Adelaide.

van Wieringen, J., 1986. Secular growth changes. In: Falkner, F., Tanner, J. (Eds.),Human Growth, second ed., vol. 3. Plenum Press, New York, NY, pp. 307-331.

Wells, J., Cole, T., Bruner, D., Treleaven, P., 2008. Body shape in American and British adults: between-country and inter-ethnic comparisons. Int. J. Obes. 32,152-159.

World Health Organisation, 2000. Obesity: Preventing and Managing the Global Epidemic. World Health Organisation, Geneva. 